Article

\title{
The Personal Viewpoint on the Meaning of Tranquility Affects the Appraisal of the Urban Park Soundscape ${ }^{\dagger}$
}

\author{
Karlo Filipan ${ }^{1, *, \ddagger}$, Michiel Boes ${ }^{1}$, Bert De Coensel ${ }^{1}$, Catherine Lavandier ${ }^{2}$, Pauline Delaitre ${ }^{2}$, \\ Hrvoje Domitrović ${ }^{3}$ and Dick Botteldooren ${ }^{1}$ \\ 1 Department of Information Technology, Ghent University, Research group WAVES, 9052 Ghent, Belgium; \\ michiel.boes@ugent.be (M.B.); bert.decoensel@ugent.be (B.D.C.); dick.botteldooren@ugent.be (D.B.) \\ 2 Equipes Traitement de l'Information et Systèmes, Université de Cergy Pontoise, \\ 95302 Cergy-Pontoise, France; catherine.lavandier@u-cergy.fr (C.L.); pauline.delaitre@u-cergy.fr (P.D.) \\ 3 Department of Electroacoustics, Faculty of Electrical Engineering and Computing, University of Zagreb, \\ 10000 Zagreb, Croatia; hrvoje.domitrovic@fer.hr \\ * Correspondence: karlo.filipan@ugent.be; Tel.: +32-9-264-3325 \\ $+\quad$ This paper is an extended version of our paper published in Botteldooren, D.; Filipan, K.; Boes, M.; \\ De Coensel, B. How the meaning a person gives to tranquility could affect the appraisal of the urban park \\ soundscape. In Proceedings of the 43rd International Congress on Noise Control Engineering (Inter-Noise \\ 2014), Melbourne, Australia, 16-19 November 2014; pp. 1-6. \\ $\ddagger$ Current address: iGent Technologiepark-Zwijnaarde 15, 9052 Gent, Belgium.
}

Academic Editor: Jian Kang

Received: 30 September 2016 ; Accepted: 11 January 2017 ; Published: 17 January 2017

\begin{abstract}
Previous research has shown that tranquil areas in the city, such as urban parks, are usually perceived as positive and have a restorative effect on visitors. However, visitors could experience these spaces differently depending on the meaning they assign to the concept of tranquility. To investigate how individuals' personal views on tranquility affect their perception of the sonic environment, a soundscape study was conducted in several city parks in Antwerp, Belgium. Mobile sound measurements were combined with a questionnaire survey amongst 660 park visitors. Within the survey, the participants' viewpoint on tranquility was evaluated using their agreement with a set of previously established prototypical statements, categorizing them into one out of three main tranquility viewpoint groups: people that associate tranquility with silence, those that associate it with hearing natural sounds, or those that associate it with social relationships. Next to this, the sounds that participants had heard during their visit were noted, and their perception of the overall quality of the soundscape and the degree to which it matched their expectation were assessed. Results show that the park visitors who associate tranquility with natural sounds or to silence are more often found amongst those that report hearing mechanical sounds a lot. The same groups of visitors rate the overall quality of the sonic environment of the park more often bad to very bad. These findings suggest that park visitors pay attention more to the sounds they do not expect to hear, and that the higher their expectations about the soundscape, the more critical they become in their appraisal of the soundscape.
\end{abstract}

Keywords: soundscape; tranquil areas; urban parks; personal viewpoint

PACS: 43.66.Lj; 43.50.Qp; 43.50.Rq; 43.28.Hr

\section{Introduction}

People widely acknowledge urban parks as places for appreciating tranquility and a restorative soundscape. The term soundscape has previously been defined by different practitioners such as 
composers, acousticians, architects and psychologists [1-3]. Within the ISO 12913-1 international standard, the term soundscape is defined as "the acoustic environment as perceived or experienced and/or understood by a person or people, in context" [4]. The soundscape is generally considered as not equal to the sound environment, and therefore not measurable using only standard sound measurement equipment. Fundamentally, soundscape is shaped within a context of a person-environment interaction. This context is induced by all sensory stimulations, most importantly by auditory and visual observations. However, other senses, such as smell and touch variably contribute to overall perception. Additionally, context is also shaped by the knowledge that people have accumulated about the space, its use, purpose and cultural meaning, people's motivations and purposes, associated activities and other factors [5].

The soundscape of urban environments has been thoroughly investigated during recent years [6-8]. Even though the soundscape of urban parks only represents a small subset of all existing soundscape types, its context has been reasonably well described [9-11]. In this description, urban parks are frequently regarded as calm and tranquil areas within the liveliness of the city. Moreover, the concept of tranquility has been studied in various research areas closely related to soundscape. For instance, a direct brain response with relation to perceived tranquility was measured with neural imaging [12]. Additionally, the tranquility of natural places has been investigated and evaluated with established soundscape indicators [13]. Finally, tranquility is considered to be an important characteristic of the soundscape of religious spaces [14].

A study on linguistic representations of tranquility has been conducted among the French population $[15,16]$. In this research, three major groups of people were identified: those who associate tranquility to social relationships, those that mention sounds, in particular natural sounds with relation to tranquility, and those that focus on silence. Although these categories were quantitatively assessed for "zones calmes" (quiet areas), there has been no attempt to relate these findings to the perception of the sonic environment. Therefore, linking these findings with widely used soundscape evaluation methods could provide new insights into the assessment of urban parks.

In a broader context, this paper focuses on the influence of the viewpoints or beliefs related to tranquility and the way they affect the perception of the sonic environment. The present study combines a tranquility viewpoints extraction methodology with the soundscape perception data from questionnaires administered in urban parks, and aims to quantitatively and directly link this personal factor to the perception of the sonic environment in urban parks. Based on the theoretical consideration on the perception of soundscape given in [17], two hypotheses are formulated.

A first hypothesis relates directly to attention mechanisms, the component of sensory processing that prioritizes on the basis of motivational relevance [18]. Known sounds trigger attention more than unknown sounds and a keen interest in these sounds may sustain voluntary attention to them. Thus, people associating tranquility to hearing specific sounds, in particular natural ones, may have a better knowledge and sensitivity for them and hence a higher probability for noticing these sounds. Moreover, it could also be expected that these people report hearing natural sounds more often when asked about their experience while visiting a park. Similarly, people that associate tranquility to social sounds could be expected to notice human voices more often. Recently, it was observed that environment-related attitudes influence perceptions of green space, in particular that nature-oriented attitude leads to valuing natural sounds more highly [19]. This result could support our first hypothesis, yet the questions about natural sounds used in this study were more oriented towards valuation than towards observation. At the higher level of auditory object formation, incongruent sound may, however, also attract attention more often. Nevertheless, incongruence depends primarily on the presence of other sounds and is not expected to be strongly influenced by beliefs on tranquility [20]. In summary, based on the first hypothesis, one could expect that people who associate tranquility with hearing natural sounds would report hearing more natural sounds than their peers. Additionally, people who associate tranquility with social relationships could be expected to report hearing more sounds of people. 
A second hypothesis links tranquility viewpoints to expectations, the component of sensory processing that interprets a stimulus with respect to its prior likelihood. Therefore, expected sounds do not add information about a place and thus would most likely not be noticed and remembered when a person is asked to describe what he or she had heard during a park visit. The role of consistency with schema expectation in remembering elements from a scene has been established in earlier studies [21]. Therefore, in our study, people that associate tranquility to hearing natural sounds would notice non-natural sounds more often and people associating tranquility to silence would hear all sounds more often than others. In addition, although a mild violation of expectation that does not offend the listener may be appraised as pleasing [22], expectation violation is assumed to trigger mainly negative appraisals. Because of the overall sonic environment, parks in urban settings are less likely to match expectations of the listeners who associate tranquility with natural sounds or silence. Hence, these people would not only notice unexpected sounds more often, they would also appraise the soundscape as less pleasing.

Section 2 of this paper introduces the methodology for extracting the viewpoints on tranquility. Section 3 describes the case study in Antwerp, on which data from the hypotheses are tested, and Section 4 discusses the results. Note that part of the results presented in this paper were published in a previous conference paper [23].

\section{Main Viewpoints on Tranquility}

In order to provide an overview of the different meanings given to tranquility, an online survey has been conducted in France using Q-methodology with 302 participants $[15,16]$. This study revealed the main beliefs shared by different groups of the population. A brief description of the methodology is given in this section, but, for the complete study, we refer to [16].

\subsection{Methodology of Extraction}

The participants were asked to rank 47 sentences (called Q-statements) depending on their agreement with the specific statement. The statements were chosen based on the earlier lexicographic studies [24]. In a survey, participants placed the statements into a pyramid with an 11-point scale from "mostly disagree" $(-5)$ to "mostly agree" $(+5)$. A matrix $(n \times p)$, where $n$ stands for the number of statements (47) and $p$ for the number of participants (302), was created from the obtained data. The $x_{i j}$-th element of the matrix corresponds to the agreement score on the scale for statement $i$, as given by person $j$. To identify similar participants, a principal component analysis (PCA) [25] was conducted, where the objects represent the statements, and the participants the variables. A Varimax rotation [26] was implemented in order to maximize the correlations $r_{j k}$ between the variables (persons) and the components.

Each component was then interpreted as a typical viewpoint shared by all of the statistically significant correlated members. Afterwards, only exclusive contributors, i.e., correlated to one component alone, were kept for the interpretation of each component. The weights of each exclusive contributor $w_{j k}$ were defined (Equation (1)) from the correlation coefficients $r_{j k}$ between the corresponding contributor (person) $j$ and component $k$ :

$$
w_{j k}=\frac{r_{j k}}{1-r_{j k}^{2}} .
$$

Finally, the weighted mean scores in the pyramid were ranked again by giving the lowest score -5 to the two lowest values, -4 for the three following values, and so forth until reaching +5 for the two highest values. This final pyramid corresponded to "factor array" [27] and provided understanding of beliefs shared by the members contributing exclusively to each component. 


\subsection{Viewpoint Groups}

Within the French survey, nine components were interpreted as nine different meanings of tranquil areas, although only three included more than 10 exclusive contributors.

\subsubsection{The "Social Relationships" Group}

This group consisted of people who agreed with the idea that tranquility could be experienced with other people. For them, a quiet area is symbolized as a shared space which facilitates social relationships and enables spending time with others. In this group, the percentage of people who live in city centers $(53 \%)$ is found to be larger than in the initial corpus.

\subsubsection{The "Natural Sound Sources" Group}

Exclusive contributors to this group agreed with the sentences "in a quiet area, there is nature" $(+5)$; "the presence of birds reinforces the tranquility" $(+4)$; and "the presence of water contributes to the tranquility" $(+4)$. In turn, this experienced natural atmosphere provided them with escape from the urban context. No special profile of the members of this group has been found. Therefore, this viewpoint was shared by various demographic groups.

\subsubsection{The "Silence" Group}

People belonging to this group mostly agreed with the sentence "a quiet area must be silent" $(+5)$. Accordingly, they stated that they did not desire any sound such as sounds from people's activities or facilities. This group mainly consisted of men (71\%), compared to the initial corpus $(45 \%)$. The members of this group were also older than the others ( $36 \%$ were over 50 years old, compared to $17 \%$ in the initial corpus), and $29 \%$ of exclusive contributors stated that they held management work positions.

\section{Antwerp Parks Survey Campaign}

\subsection{Study Area}

This study was conducted during 22 days in August and September 2013. The data were gathered in eight different urban parks located in the city of Antwerp (Figure 1). Antwerp has a population of about 500,000 people and an economy centered around an important European harbor. Therefore, the traffic going to and from the city has a big impact on the urban sound environment.

The investigated parks, chosen in cooperation with the city council environmental authority, were expected to thoroughly represent the Antwerp park environment. They were located in different urban areas: city center (Stadspark), near the big highway junction (Rivierenhof) and in various living districts (six other parks). Moreover, their sizes also varied considerably from the smallest park (Bischoppenhof, around $0.03 \mathrm{~km}^{2}$ in size) to the largest park (Rivierenhof, around $1.3 \mathrm{~km}^{2}$ in size).

\subsection{People}

During the survey campaign, 660 participants were interviewed inside the investigated parks. The average age of the participants was 49.2 years while the standard deviation was 19.3 years (minimum and maximum age was 18 and 93 years, respectively). In total, 301 male participants ( $46 \%$ of the total sample) and 359 female participants (54\% of the total sample) were interviewed. Most of the participants reported that they had a normal hearing (579 participants); however, 81 participants reported having one or more problems related to hearing: 32 participants reported being sensitive to noise, 16 reported using a hearing aid, 19 reported suffering from tinnitus and 27 participants reported they had other hearing problems. Participants voluntarily took part in the questionnaire. Nevertheless, an additional incentive was given by the possibility of winning a lottery prize of 100 euros. 


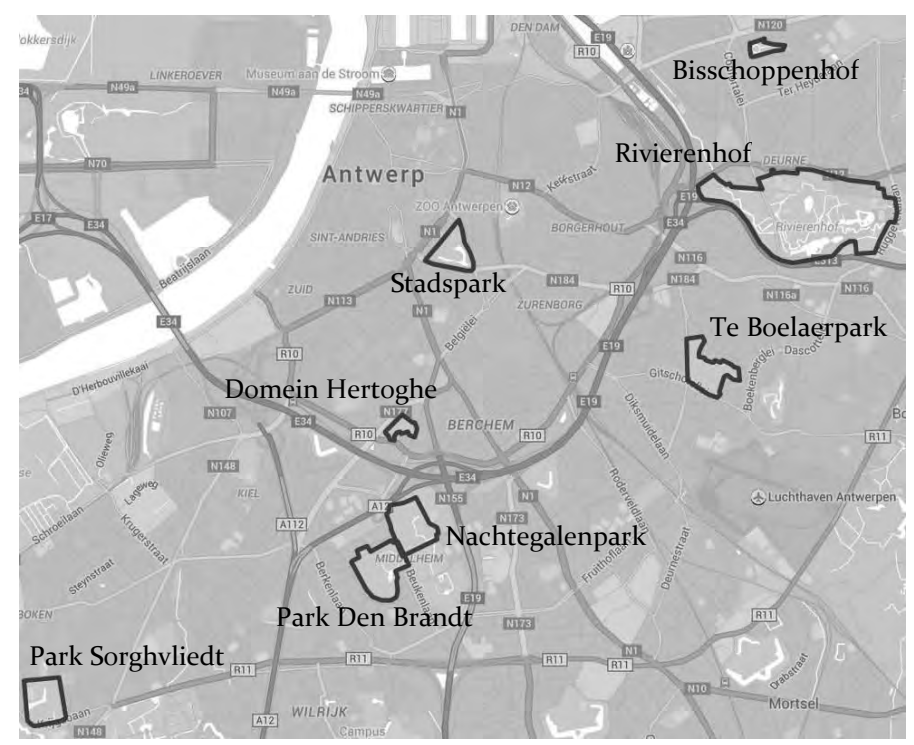

Figure 1. Locations of the eight parks in the city of Antwerp studied in the survey campaign.

\subsection{Mobile Measurements}

Measurements were performed using mobile recording devices carried in backpacks by two to three people per park. Researchers carrying the backpacks were specifically instructed to mind their walking manner in order not to disturb the recorded sonic environment. Paths were chosen to cover the whole area of the park while no specific walking directions were given. Additionally, approximately every half hour, the researcher would stop to make stationary recordings by placing the backpack on the closest bench for $10 \mathrm{~min}$. Moreover, in order to capture the sound environment outside the park, the researchers also walked on the roads surrounding the park.

The devices used in measurements were custom-made, Linux-based sensor network mobile nodes [28] adapted to incorporate both sound and location recording. Therefore, the collected data comprised sound recordings, 1/3-octave band levels saved eight times per second, as well as GPS positions recorded one time per second. To facilitate data processing and presentation, spectral levels and GPS values were later transferred to a spatial database.

A set of indicators characterizing the sonic environment was extracted from the stored measurement data. These indicators were calculated from recorded 1/3-octave band values selected with a moving window of one minute duration and $10 \mathrm{~s}$ time step. Thus, every $10 \mathrm{~s}$, one value was calculated, integrated over the last minute. Consequently, there was a $50 \mathrm{~s}$ overlap of data with the previous indicator value. Finally, location data (GPS positions) were included and related to the acoustic indicators by interpolating the dataset to the same 10-second period division.

\subsection{Soundscape Questionnaire}

A questionnaire (in Dutch) was created based on previous research [6,29] and a survey was conducted amongst park visitors. The interviewers aimed to collect at least 80 completed questionnaires in the central area of each park. The questionnaire included questions about the visitors' general profile, their use of the park, their evaluation of the soundscape along a number of perceptual dimensions [6], their perception of the environmental quality of the park and other factors.

In particular, the questionnaire inquired about the noticing of sound sources during the park visit. The three groups of sounds were listed as "human sounds (talking people, playing children, ....)", "natural sounds (wind in the leafs, birds, water, ...)" and "mechanical sounds (traffic, airplanes, machines, small electronic accessories, ...)". Participants were asked to rank hearing sounds in these categories on a 5-point ordinal category scale with categories: "not at all", "a little", "moderately", "much" and "very much". 
Another question examined the participants' agreement with the statement "the sounds in this park are the sounds that one expects to hear in a park". The answers were listed on a 5-point ordinal category scale with values: "completely agree", "agree", "neither agree/nor disagree", "disagree" and "completely disagree". Additionally, participants were asked on the overall quality of the sonic environment during their visit. Their opinion was marked on the 5-point ordinal category scale with labels: "very bad", "bad", "neither good/nor bad", "good" and "very good".

Finally, participants were asked, in a direct question, on their opinion about the purpose of a park in general. Corresponding to the tranquility viewpoint groups: "Natural sound sources", "Silence" and "Social relationships" (Section 2.2), three mutually exclusive options were provided for park as a: "place for appreciating nature", "place for appreciating silence" and "place for meeting other people", and the participants were asked to select only one option.

\subsection{Tranquility Statements}

The questionnaire also included the 13 statements on tranquility presented in Table 1 . They were selected from the 47 statements used in the French population quiet areas study [16] to be the most differentiating between tranquility viewpoints (Section 2). In accordance with the methodology, participants ranked their preference on an ordinal scale with 11 numbers ranging from -5 to +5 with the labels only on both ends: "do not agree at all" $(-5)$ and "completely agree" $(+5)$.

The degree of similarity between the prototypical tranquility viewpoint and the participants' responses was extracted by connecting the prototypical group markings from the French study (Table 1) with the participants' answers (ranging from -5 to +5 ) on the same 13 tranquility statements.

For this, the value $m_{j i}$ (i.e., the response of participant $j$ to statement $i$ ) was first selected. At the same time, the prototypical group marking $g_{k i}$ (all values shown in Table 1) for each tranquility viewpoint group $k$ and statement $i$ was obtained. Secondly, using the data for all 13 tranquility statements, the degree of similarity $G_{j}(k)$ between the response of participant $j$ and the group $k$ was calculated using the overlap-integral method (Equation (2)). Therefore, three values representing degree of similarity to three tranquility groups (Section 2.2) were assigned to each of the 660 participants. Finally, $G_{j}(k)$ can be interpreted as the partial membership of person $j$ to tranquility viewpoint group $k$ in a probabilistic way:

$$
G_{j}(k)=\frac{\sum_{i} m_{j i} g_{k i}}{\sqrt{\sum_{i} m_{j i}^{2}} \sqrt{\sum_{i} g_{k i}^{2}}} .
$$

\subsection{Relative Membership to Tranquility Groups}

Relative membership to each tranquility viewpoint group was introduced to compare people's responses to other questions, taking into account their specific tranquility viewpoint group. Firstly, the degree of similarity (partial membership) $G_{j}(k)$ (Equation (2)) for each participant $j$ and tranquility viewpoint group $k$ was normalized to the average membership of group $k$ between all 660 responses (Equation (3)). $G_{j}^{\prime}(k)$ can be interpreted as how much more participant $j$ belongs to the tranquility viewpoint group $k$ than the average over all participants:

$$
G_{j}^{\prime}(k)=\frac{G_{j}(k)}{\frac{1}{N} \sum_{j} G_{j}(k)}, N=660 .
$$


Table 1. Tranquility statements used in the Antwerp parks survey campaign with their corresponding reference number to the French quiet areas study [16]. Prototypical group markings $\left(g_{k i}\right)$ are provided for each statement $i$ and three tranquility groups $k$ : (1) - "Social relationships" group, (2) - “Natural sound sources" group, (3)-“Silence” group.

\begin{tabular}{|c|c|c|c|c|c|c|}
\hline$i$ & No. in [16] & Survey Statement & Translated Statement & (1) & (2) & (3) \\
\hline 1 & 11 & Een rustgevende plek is een toevluchtsoord & A quiet area is a refuge & 3 & 1 & 5 \\
\hline 2 & 29 & Achtergrondgeluid stoort mij niet & Background sound does not bother me & 1 & -4 & -4 \\
\hline 3 & 22 & Een plek is rustgevend als er geen kinderen zijn & A quiet area is an area without children & -5 & -3 & 0 \\
\hline 4 & 33 & Een rustgevende plek moet stil zijn & A quiet area must be silent & -2 & 0 & 5 \\
\hline 5 & 20 & Een rustgevende plek nodigt uit om een tijdje te blijven hangen & In a quiet area, I can linger & 4 & 3 & 3 \\
\hline 6 & 13 & Een rustgevende plek wordt nog rustgevender door het contrast met de omgeving & A quiet area is even quieter when it contrasts with its surroundings & 2 & -1 & 3 \\
\hline 7 & 34 & Het is rustgevend als specifieke geluiden hoorbaar zijn & Tranquility, it is being able to hear specific sounds & 3 & 2 & 1 \\
\hline 8 & 44 & Op een rustgevende plek kunnen er winkeltjes en horeca zijn & In a quiet area, there may be shops & 1 & -2 & -3 \\
\hline 9 & 46 & Op een rustige plek ben ik bang om alleen te zijn & In a quiet area, I am afraid of being alone & -4 & -5 & -5 \\
\hline 10 & 42 & Rust is er om te delen met anderen & Tranquility can be experienced with others & 5 & 0 & 2 \\
\hline 11 & 32 & Vogels dragen bij tot het rustgevende karakter van een plek & The presence of birds reinforces the tranquility & 0 & 4 & 1 \\
\hline 12 & 36 & Water draagt bij tot het rustgevende karakter van een plek & The presence of water contributes to the tranquility & 4 & 4 & 2 \\
\hline 13 & 47 & Een plek kan rustgevend zijn, zelfs met voorbijgangers & We can be tranquil, even if there is movement around & 4 & -3 & -4 \\
\hline
\end{tabular}


Secondly, the set of persons $j$ that answered value $l$ to question $Q$ (e.g., "not at all" for question "hearing human sounds") was selected. Finally, the relative membership $H_{Q, l}$ (Equation (4)) was calculated as an average of the normalized degree of similarity $G_{j}^{\prime}(k)$ over the persons that selected the $l$-th answer to question $Q$ (the sum in denominator in Equation (4) effectively represents this number of participants). Additionally, for the complete representation of the selected dataset, standard deviations were also calculated:

$$
H_{Q, l}(k)=\frac{\sum_{j \mid Q_{j=l}} G_{j}^{\prime}(k)}{\sum_{j \mid Q_{j=l}} 1} .
$$

With a similar procedure, relative membership to each tranquility viewpoint group was also extracted for the participants from each park separately. To this purpose, in Equation (4), question $Q$ was evaluated as the park location and answer $l$ as the specific park.

\section{Results and Discussion}

\subsection{Tranquility Groups in Antwerp Parks}

Visitors of the surveyed parks were classified according to their tranquility viewpoints extracted with the procedure described in Section 3.5. Each participant was then assigned to only one of the three tranquility groups by selecting the group with the largest value $G_{j}(k)$. In turn, it was found that $74 \%$ of the 660 interviewed participants adhere to the viewpoint that a tranquil park is a place for social relationships, whereas only $18 \%$ associate a tranquil park to silence. The remaining group $(8 \%)$ identifies their tranquility viewpoint with natural sound sources. This differs from the results previously reported by Lavandier and Delaitre [16], where $62 \%, 57 \%$ and $14 \%$ of participants associated tranquility to social relationships, natural sound sources and silence, respectively.

This difference could be explained by various factors. Firstly, in the French population study, it was observed that the participants could have multiple tranquility viewpoints, not limited to the three major groups (Section 2.2). Nevertheless, for the prototypical response values (Table 1), only the three strongest principle components for tranquility viewpoints from the French study were retained. Additionally, for this analysis, each participant was assigned to only one tranquility viewpoint group. Finally, it should be noted that this study's context is urban parks, in contrast to the French study, in which tranquil areas in a general sense were considered. Tranquility in urban parks may be less associated to hearing natural sounds, than tranquility in general. Therefore, this difference might explain the relative lack of tranquility viewpoints related to natural sound sources in this study, as compared to the earlier one [16].

\subsection{Noticing Sounds}

Relative membership to tranquility viewpoint (Equation (4)) was evaluated to observe how tranquility viewpoint affects people's perception of soundscape. Since previous work [30-32] has found a strong relationship between the sounds that people report to have heard while in a public place and the pleasantness of the soundscape, the relationship between the sounds that people have heard and their membership to a tranquility viewpoint group was assessed first. For brevity, the fact that people reported that sounds belonging to a specific category (mechanical, natural, human) have been frequently heard is labeled as noticing these sounds.

Survey participants answered the question about hearing different categories of sound on a 5-point ordinal category scale. The calculated membership to tranquility viewpoint groups is furthermore assessed as a continuous variable as it aggregates the answers from an 11-point scale and 13 questions with an overlap integral method (Equation (2)). In Figure 2, the results are therefore shown as the relative membership to tranquility viewpoint groups, i.e., the average of the normalized degree of similarity calculated by Equations (3) and (4), for different answer categories on the questions about 
hearing particular sounds. This may look slightly unconventional, as it is more popular to show expected effects as a function of expected cause.
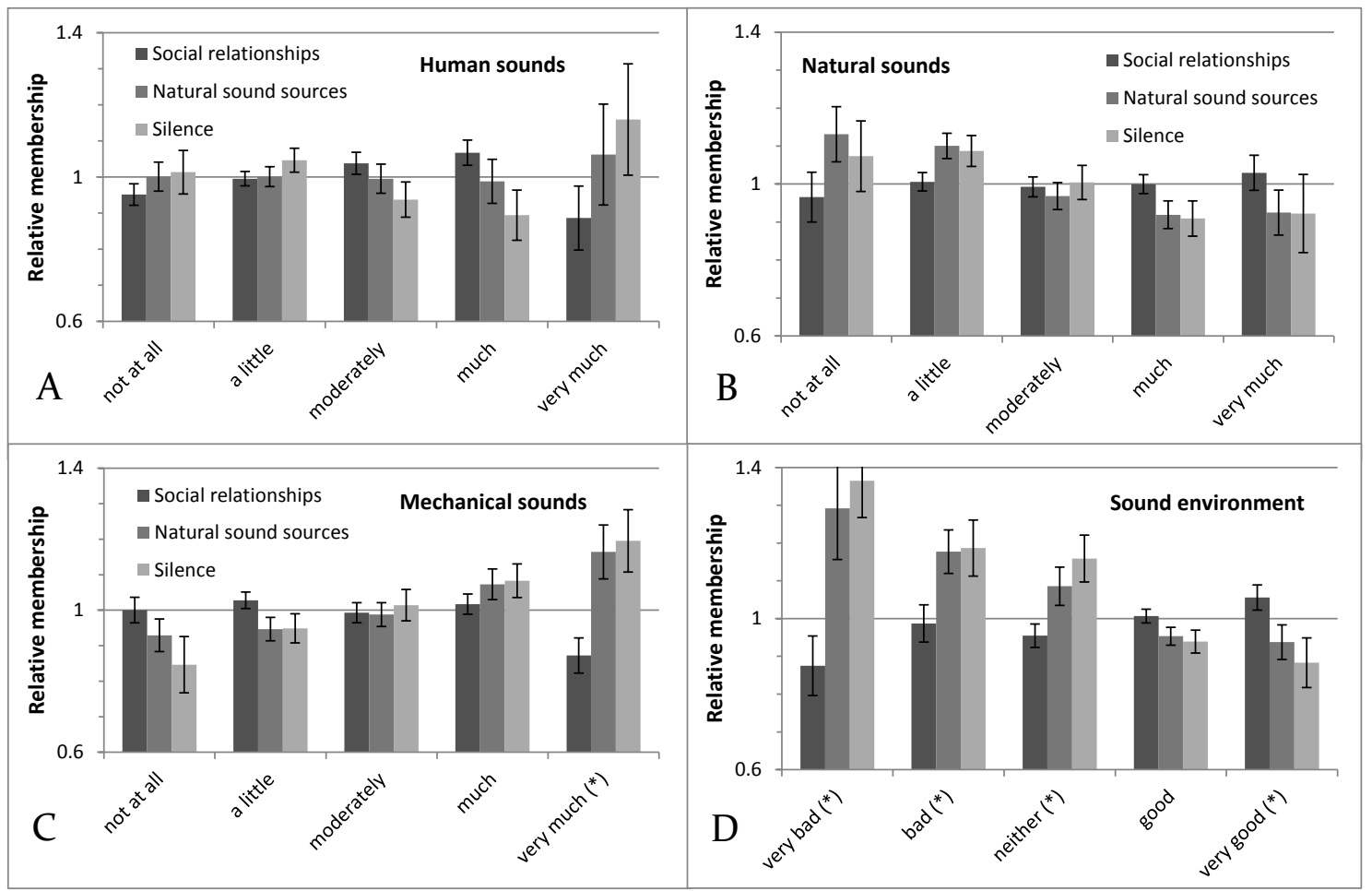

Figure 2. Relative membership to tranquility viewpoint groups shown in relation to hearing sound sources: (A) human, (B) natural and (C) mechanical. In (D): relative membership in relation to evaluation of the quality of the sonic environment is presented. Whiskers indicate one standard error of the dataset. A star indicates statistically significant difference confirmed by the analysis of variance between tranquility groups within one answer category.

Given that the descriptive analysis shows some possible trends, the statistical significance was assessed using the Kendall rank correlation coefficient $\left(\tau_{b}\right)$ (statistical analyses were performed using the Python programming language with Scipy [33] (analysis of variance (ANOVA) and correlation) and Statsmodels [34] (Tukey test) modules). Table 2 shows this correlation coefficient between noticing sounds belonging to one of the three categories (human sounds, natural sounds, mechanical sounds) and the relative adherence to the tranquility viewpoint groups ("Social relationships", "Natural sound sources", "Silence"). Belonging to the tranquility viewpoint group "Social relationships" (first row in Table 2) does not correlate statistically significant with noticing sounds from any of the categories, yet there is a weak trend for noticing more human sounds. However, the trends between belonging to the tranquility viewpoint group "Natural sound sources" and noticing natural sound (negative) and noticing mechanical sounds (positive) are highly statistically significant. Likewise, the positive trend between belonging to the tranquility viewpoint "Silence" and noticing mechanical sounds is statistically significant, while the negative trend between belonging to the tranquility viewpoint "Silence" and noticing natural sounds is statistically significant but also weaker. Finally, there is no statistically significant or pronounced trend between belonging to either of these last two tranquility viewpoint groups and noticing human sounds. 
Table 2. Rank correlation coefficients with significance values between participants' responses to questions on hearing sounds (human, natural and mechanical) and belonging to a specific tranquility group. In the last column, the same is shown for the question on the quality of the sonic environment.

\begin{tabular}{lcccc}
\hline \multicolumn{1}{c}{ Question: } & Human Sounds & Natural Sounds & Mechanical Sounds & Sound Environment \\
\hline Tranquility Group & & & & \\
\hline \multirow{2}{*}{ Social relationships } & $\tau_{b}=0.066$ & $\tau_{b}=0.008$ & $\tau_{b}=-0.048$ & $\tau_{b}=0.072$ \\
& $p=0.011$ & $p=0.747$ & $p=0.066$ & $p=0.006$ \\
\hline \multirow{2}{*}{ Natural sound sources } & $\tau_{b}=0.000$ & $\tau_{b}=-0.118$ & $\tau_{b}=0.114$ & $\tau_{b}=-0.130$ \\
& $p=0.998$ & $p<0.001$ & $p<0.001$ & $p<0.001$ \\
\hline \multirow{2}{*}{ Silence } & $\tau_{b}=-0.060$ & $\tau_{b}=-0.073$ & $\tau_{b}=0.106$ & $\tau_{b}=-0.142$ \\
& $p=0.022$ & $p=0.005$ & $p<0.001$ & $p<0.001$ \\
\hline
\end{tabular}

Rank correlation only allows detecting monotonous trends. Although these already illustrate the main effect, visual inspection of Figure 2 seems to reveal that less people associating tranquility to social relationships report hearing human and mechanical sounds "very much". Only the latter is confirmed by a one-way ANOVA test: there is a statistically significant difference between the participants belonging to different tranquility groups who reported hearing mechanical sounds "very much" $(F(2,168)=5.969, p=0.003)$.

A Tukey post hoc test revealed that the relative membership of people belonging to tranquility groups "Silence" $(H=1.195, S D=0.088, p=0.006)$ and "Natural sound sources" $(H=1.164, S D=0.076$, $p=0.014)$ was statistically significantly different from the relative membership of "Social relationships" group $(H=0.872, S D=0.050)$. In brackets, $H$ represents the relative membership to the stated tranquility viewpoint group (Equation (4)), whereas $S D$ represents the standard deviation of the dataset used to calculate this relative membership (Section 3.6). Additionally, no statistically significant difference could be found between the relative memberships to tranquility groups "Silence" and "Natural sound sources" using the Tukey test.

These statistically significant trends reject the hypothesis that persons associating tranquility to social relationships would report hearing human sounds more often as well as the hypothesis that persons associating tranquility to natural sound sources would report hearing natural sounds more often as they would pay more attention to noticing these sounds.

\subsection{Quality of the Sonic Environment}

As could be expected on the basis of the known relationship between hearing particular sounds and overall quality judgment of the sonic environment and the results discussed in Section 4.2, statistically significant trends are found between relative adherence to tranquility viewpoints and judgment of the quality of the sonic environment. Indeed, the last column of Table 2 shows a statistically significant negative correlation coefficient between relative membership to the tranquility viewpoint groups "Natural sound sources" and "Silence" and the judgment of the overall quality of the sound environment. Thus, persons adhering to these tranquility viewpoints judge the quality of the sonic environment worse.

Although these statistically significant trends as a function of the appraisal of the sonic environment highlight the effect of relative membership to the tranquility viewpoints "Natural sound sources" and "Silence" on this appraisal, it is also useful to study the difference between membership of tranquility viewpoints within each of the five sonic environment quality judgment groups.

A statistically significant difference determined by one-way ANOVA between tranquility groups was observed within several categories of the overall quality appraisal of the sonic environment. The difference was found for the responses: "very bad" $(F(2,30)=6.147, p=0.006)$, "bad" $(F(2,162)=3.373, p=0.037)$, "neither good, nor bad" $(F(2,366)=4.353, p=0.014)$ and "very good" $(F(2,273)=3.107, p=0.046)$. For the responses "neither good, nor bad" and "very good", results 
from Tukey post hoc tests revealed that the difference is statistically significant only between the tranquility groups "Silence" and "Social relationships" (with Tukey test significance levels of $p=0.011$ for the response "neither good, nor bad", and $p=0.041$ for the response "very good"). Furthermore, Tukey tests showed that the response "very bad" had a statistically significant difference between the groups "Natural sound sources" and "Social relationships" $(p=0.025)$ as well as between the groups "Silence" and "Social relationships" ( $p=0.007)$. For the response "bad", no statistically significant result was found with the post hoc test.

The questionnaire also asked about the degree to which the sounds that people heard while visiting a park matched their expectations (Section 3.4). The Kendal correlation coefficient shows no statistically significant correlation between reported matching expectations and the relative membership to the "Social relationships" tranquility group. There is, however, a statistically significant negative correlation between the degree of matching of the sounds that people heard with their expectations and the relative membership to tranquility group "Natural sounds sources" $\left(\tau_{b}=-0.121, p<0.001\right)$ and "Silence" $\left(\tau_{b}=-0.109, p<0.001\right)$.

Both statistically significant trends discussed in this section may be indicative of the fact that persons associating tranquility to hearing natural sounds, or to silence, do not find their expectations matched in the city parks of Antwerp, and, therefore, also tend to rate the quality of the sonic environment worse than other people visiting the park. It should nevertheless be noted that the causality chain has not been proven. It might be that the persons belonging to these tranquility viewpoint groups are more demanding on the sonic environment when assessing its quality and, at the same time, have higher expectations than those associating tranquility to social relationships.

\subsection{Differences between Parks}

In previous sections, a relationship was established between some tranquility viewpoints and sounds that persons visiting a park notice. Similarly, a relationship between some tranquility viewpoints and the overall assessment of the quality of the sonic environment was established. In this section, the influence of the park where the persons were encountered is studied in relation to the tranquility viewpoint and whether visitors' expectations were matched. Therefore, relative membership was also calculated for people interviewed in each park (Equation (4)).

The results show that, although the viewpoint on tranquility may have an influence on the park that is visited, this influence seems not to be statistically significant. Indeed, one could imagine plenty of other factors such as proximity, visual environment, infrastructure, etc., that affect which park people select.

In addition, Table 3 presents the percentage of the persons that stated that the sounds heard in the park matched their expectations. In particular, participants who stated "agree" or "completely agree" on the questionnaire statement "the sounds in this park are the sounds that one expects to hear in a park" (Section 3.4) were considered to have the expectations of the sonic environment of the park matched.

Whether or not the sound environment matches the expectations of the park visitor could depend on many different factors. For example, the intrinsic quality of the sound environment in the park could match expectations of park visitors in general. However, a possible deviation in the sonic environment, as compared to the usual situation that the visitor might know from earlier visits, could also lead to an expectation mismatch. Finally, the expectations regarding the sounds a visitor would like to encounter in a park could be related to the tranquility viewpoint to which that person adheres. However, no statistically significant trends were found with Pearson correlation analysis. Therefore, at the park level, a multitude of other factors influencing whether the sonic environment matches expectations obscures the trend observed for some viewpoints seen at the level of the individual (Sections 4.2 and 4.3). 
Table 3. Membership of the tranquility viewpoint groups normalized to indicate in which parks persons adhering to these viewpoints are found more often than average (arrows point to difference of more than $5 \%$ to overall average). Matching expectations are shown with the percentage of the visitors that stated "agree" or "completely agree" on the questionnaire statement "the sounds in this park are the sounds that one expects to hear in a park" (Section 3.4). The last column presents the average and standard deviation of the 50-percentile A-weighted sound pressure level from data aggregated over the whole park (Section 3.3).

\begin{tabular}{|c|c|c|c|c|c|}
\hline \multirow{2}{*}{ Park } & \multicolumn{3}{|c|}{ Tranquility Viewpoint } & \multirow{2}{*}{ Matching Expectations (\%) } & \multirow{2}{*}{$L_{A 50,}(\mathrm{dBA})$} \\
\hline & Social Relationships & Natural Sound Sources & Silence & & \\
\hline Bisschoppenhof & $0.929 \downarrow$ & $0.905 \downarrow$ & 0.969 & 88 & $49.7 \pm 3.6$ \\
\hline Domein Hertoghe & 0.991 & 1.004 & $1.079 \uparrow$ & 86 & $52.9 \pm 5.2$ \\
\hline Nachtegalenpark & 1.001 & $1.055 \uparrow$ & $0.921 \downarrow$ & 69 & $53.6 \pm 5.1$ \\
\hline Park Den Brandt & 1.002 & $1.094 \uparrow$ & $1.093 \uparrow$ & 79 & $47.9 \pm 4.0$ \\
\hline Park Sorghvliedt & 1.006 & $0.933 \downarrow$ & $0.948 \downarrow$ & 93 & $51.9 \pm 4.8$ \\
\hline Rivierenhof & 1.002 & 0.993 & 1.048 & 71 & $55.9 \pm 5.4$ \\
\hline Stadspark & 0.996 & 0.984 & $0.946 \downarrow$ & 73 & $56.2 \pm 4.1$ \\
\hline Te Boelaerpark & $1.070 \uparrow$ & 1.030 & 0.997 & 66 & $53.9 \pm 4.4$ \\
\hline
\end{tabular}

\subsection{Sound Levels in the Parks}

Although this publication and the underlying study do not aim at identifying physical indicators for the quality of the sonic environment of parks, the reader may be interested in sound levels in the parks. Therefore, Table 3 also presents the 50-percentile A-weighted sound pressure level $\left(L_{A 50}\right)$, an indicator which is often reported to relate well to people's overall tranquility experience of a sonic environment [35]. The values in this table represent an average over the whole park, calculated from one-minute indicator values obtained using the procedure described in Section 3.3.

When comparing the levels between the parks, the range in level spans $8.3 \mathrm{~dB}$, with Park Den Brandt having the highest $L_{A 50}$ and Stadspark having the lowest $L_{A 50}$. Accordingly, visitors who associate tranquility to silence (and natural sound sources) were found more often than average in Park Den Brandt. In the same manner, visitors who were found in Stadspark adhere less often to the tranquility viewpoint associated with silence. However, no statistically significant trend can be found from Kendall rank correlation between the tranquility group memberships in the investigated parks and the $L_{A 50}$. This is further illustrated by Domein Hertoghe. For this park, the relative membership of the visitors to tranquility groups "Silence" and "Natural sound sources" is higher than the average of both groups, and, moreover, the sounds heard in this park match expectations, yet the $L_{A 50}$ is slightly higher than the average over parks. This could potentially be explained by the observation that this park is almost completely covered by forest and green paths and the knowledge that visual elements contribute to the perception of tranquility [13].

\subsection{Reported Park Purpose in Relation to Derived Tranquility Viewooints}

Rather than identifying tranquility viewpoints from the 13 questions, as explained in Section 3.5, one could attempt to deduct this viewpoint from a more direct question about the belief on the purpose of a park. Figure 3 compares the tranquility viewpoint between groups of people reporting different purposes of a park. On the direct question on park purpose, most respondents answer that a park is a place for appreciation of nature.

Membership of tranquility viewpoint groups was compared with a one-way ANOVA within park purpose groups. Results for the answer for park as a place for appreciating nature were not statistically significant $(F(2,1320)=1.089, p=0.337)$. However, for park as a place for appreciating silence, the analysis shows statistically significant difference between groups $(F(2,396)=21.541, p<0.001)$. A Tukey post hoc test unveiled that the difference was statistically significant for all comparisons. In particular, statistical significance of $p$ less than 0.001 was identified between "Natural sound sources" $(H=1.049, S D=0.040)$ and "Silence" $(H=1.269, S D=0.048)$ tranquility viewpoint groups as well as "Social relationships" ( $H=0.893, S D=0.034)$ and "Silence". In brackets, $H$ represents the relative 
membership to the stated tranquility viewpoint group (Equation (4)) and $S D$ represents the standard deviation of the dataset used to calculate this relative membership (Section 3.6). Additionally, relative membership to "Natural sound sources" $(H=1.049, S D=0.040, p=0.019)$ was found to be statistically significantly higher than to "Social relationships" $(H=0.893, S D=0.034)$.

For persons that identify a park as a place for meeting other people, statistically significant difference between the groups of people belonging to different tranquility groups was found $(F(2,255)=8.611, p<0.001)$. However, results from a Tukey test suggest that the statistical significance is only between people associating tranquility to silence $(H=0.691, S D=0.073, p<0.001)$ and those associating it to social relationships $(H=1.033, S D=0.034)$. For comparison of people belonging to "Natural sound sources" tranquility group $(H=0.870, S D=0.061)$ and to two other groups, no statistically significant difference was found.

The difference between the results for the direct question on the purpose of a park and the results from the indirect viewpoint extraction method is most obvious for people stating that they are considering parks as places where they can appreciate nature. Within this group, each tranquility viewpoint is equally present. However, people that explicitly stated that they were considering a park as a place for appreciating silence also belong more frequently to the group that associates tranquility to silence. Similarly, the last group that perceives a park as a place for meeting people also puts an emphasis on social relationships different to the two other tranquility groups. Thus, for these latter categories, the direct question could be used as a proxy for deriving the tranquility viewpoint.

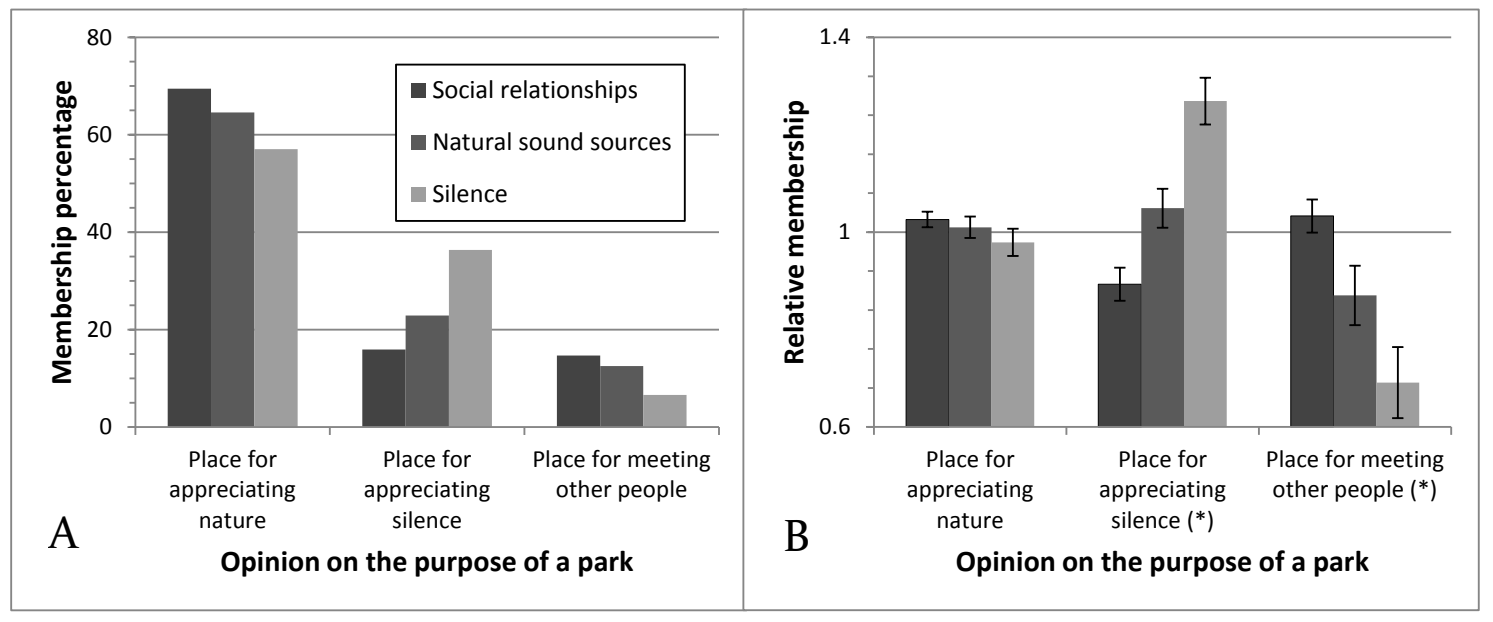

Figure 3. Membership of tranquility viewpoint groups, as a function of the response to the direct question on park purpose: (A) percentages of people responding to an opinion statement in each tranquility group; (B) relative membership to tranquility group per opinion on the park purpose. In (B): whiskers correspond to one standard error, and stars indicate statistically significant difference confirmed by analysis of variance between tranquility groups.

\section{Conclusions}

In this study, the influence of a particular contextual factor-the viewpoint of a park visitor on tranquility-on the perception of the sonic environment was investigated. To extract the viewpoint on tranquility, the results from an earlier study about the meaning of "zones calmes" (quiet areas) [16] were translated to a set of 13 most differentiating statements. A survey with 660 participants in eight urban parks in Antwerp was used to relate these viewpoints to different aspects of the soundscape.

The results obtained in this work show a tendency to falsify the first hypothesis stated in the introduction. Persons associating tranquility to hearing natural sounds do not tend to notice natural sounds more during their visit to a park. Moreover, the trend between belonging to this viewpoint group and hearing natural sounds is slightly but statistically significantly negative. Therefore, persons adhering to the "Natural sound sources" viewpoint notice less natural 
sounds than their peers, and, thus, it is expected that they do not pay more attention to the natural sounds. However, no statistically significant trend was found between noticing human sounds and belonging to the tranquility viewpoint "Social relationships". In turn, this result neither confirms nor falsifies the first hypothesis.

Turning to the second hypothesis: non-expected sounds are likely to be noticed more often than the expected ones. The results demonstrate that indeed people more frequently notice and report hearing sounds other than the ones associated with their tranquility viewpoint. In particular, it was found that the participants who belong to groups that associate tranquility to natural sound sources or to silence were more often found amongst those that reported hearing mechanical sounds a lot, and that there was a statistically significant positive trend for belonging to these tranquility viewpoint groups and noticing mechanical sounds. On the other hand, persons belonging to the tranquility viewpoint group "Social relationships" do not hear mechanical sounds more often.

In addition, we hypothesized that the people who notice these unexpected sounds would also assess soundscapes as less pleasing. In turn, statistically significant trends were found for people who associate tranquility to natural sound sources or to silence and their rating of the overall quality of the sonic environment. Therefore, people seem to pay more attention to the sounds that they do not expect to hear and rate the quality of the sound environment in Antwerp parks as less pleasing. The role of expectation is confirmed by the statistically significant negative trend between the answer to a direct question on whether the sounds that were heard matched the person's expectation and their membership to tranquility viewpoint groups "Natural sound sources" and "Silence". All of these aforementioned results confirm the statements in the second hypothesis.

Our study also showed that there is no one-to-one relationship between the viewpoint on tranquility as assessed using the proposed 13 statements and the response to a direct question on the purpose of an urban park in general. Specifically, most of the people reported a park as a place for appreciating nature. However, no statistically significant difference between the membership to tranquility groups was found. On the other hand, people that see a park as a place for appreciating silence belong to the "Silence" tranquility viewpoint group statistically significantly more often.

Finally, it was observed that, although there were slight differences in the membership of different tranquility viewpoint groups depending on the park where participants were encountered, no statistically significant differences were found. The same holds for the degree to which the park matched the expectations of the visitor as well as the overall sound level $\left(L_{A 50}\right)$ in the park. This confirms that the tranquility viewpoint assessed using the 13 statements about tranquility is orthogonal to the quality of the specific park where the person was interviewed. Consequently, it indicates that the tranquility viewpoint is a personal factor.

To summarize, this study shows that there is a diversity in opinions on the meaning of tranquility, with a vast majority stressing its social component. In addition, it was shown that this tranquility viewpoint is a personal factor that influences the sounds that are noticed during a park visit, the degree to which these sounds match expectations and the overall perceived quality of the soundscape. This conclusion, however, only holds for specific viewpoints that might be associated with more critical listening.

Acknowledgments: The research leading to these results has received funding from the People Programme (Marie Curie Actions) of the European Union's Seventh Framework Programme FP7/2007-2013/ under REA Grant agreement 290110, SONORUS "Urban Sound Planner", and from the Research Foundation Flanders (FWO-Vlaanderen) under Grant G0D5215N, ERC Runner-up project MAESTRO. Furthermore, Michiel Boes is a doctoral fellow of the Research Foundation Flanders; the support of this organization is gratefully acknowledged.

Author Contributions: Dick Botteldooren, Bert De Coensel, Catherine Lavandier and Pauline Delaitre designed the experiments; Karlo Filipan, Michiel Boes, Dick Botteldooren and Bert De Coensel performed the experiments; Karlo Filipan, Dick Botteldooren and Hrvoje Domitrović analyzed the data; Karlo Filipan, Dick Botteldooren, Catherine Lavandier and Bert De Coensel wrote the paper.

Conflicts of Interest: The authors declare no conflict of interest. 


\section{References}

1. Brown, A.L. A review of progress in soundscapes and an approach to soundscape planning. Int. J. Acoust. Vib. 2012, 17, 73-81.

2. Kang, J. Urban Sound Environment; Taylor \& Francis: London, UK, 2007.

3. Schafer, R.M. The Soundscape: Our Sonic Environment and the Tuning of the World; Destiny Books: Rochester, VT, USA, 1994.

4. International Organization for Standardization. ISO 12913-1:2014 Acoustics—Soundscape_Part 1: Definition and Conceptual Framework; International standard; International Organization for Standardization: Geneva, Switzerland, 2014.

5. Botteldooren, D.; Lavandier, C.; Preis, A.; Dubois, D.; Aspuru, I.; Guastavino, C.; Brown, A.L.; Nilsson, M.E.; Andringa, T.C. Understanding urban and natural soundscapes. In Proceedings of the Forum Acusticum, Aalborg, Denmark, 27 June-1 July 2011.

6. Axelsson, Ö.; Nilsson, M.E.; Berglund, B. A principal components model of soundscape perception. J. Acoust. Soc. Am. 2010, 128, 2836-2846.

7. Oldoni, D.; De Coensel, B.; Boes, M.; Rademaker, M.; De Baets, B.; Van Renterghem, T.; Botteldooren, D. A computational model of auditory attention for use in soundscape research. J. Acoust. Soc. Am. 2013, $134,852-861$.

8. Kang, J.; Chourmouziadou, K.; Sakantamis, K.; Wang, B.; Hao, Y. (Eds.) COST TUD Action TD0804: Soundscape of European Cities and Landscapes; Soundscape-COST: Oxford, UK, 2013.

9. Brambilla, G.; Gallo, V.; Zambon, G. The soundscape quality in some urban parks in Milan, Italy. Int. J. Environ. Res. Public Health 2013, 10, 2348-2369.

10. Jabben, J.; Weber, M.; Verheijen, E. A framework for rating environmental value of urban parks. Sci. Total Environ. 2015, 508, 395-401.

11. Liu, J.; Kang, J.; Behm, H.; Luo, T. Effects of landscape on soundscape perception: Soundwalks in city parks. Landsc. Urban Plan. 2014, 123, 30-40.

12. Hunter, M.D.; Eickhoff, S.B.; Pheasant, R.J.; Douglas, M.J.; Watts, G.R.; Farrow, T.F.D.; Hyland, D.; Kang, J.; Wilkinson, I.D.; Horoshenkov, K.V.; et al. The state of tranquility: Subjective perception is shaped by contextual modulation of auditory connectivity. NeuroImage 2010, 53, 611-618.

13. Watts, G.R.; Pheasant, R.J. Tranquillity in the Scottish Highlands and Dartmoor National Park-The importance of soundscapes and emotional factors. Appl. Acoust. 2015, 89, 297-305.

14. Jeon, J.Y.; Hwang, I.H.; Hong, J.Y. Soundscape evaluation in a Catholic cathedral and Buddhist temple precincts through social surveys and soundwalks. J. Acoust. Soc. Am. 2014, 135, 1863-1874.

15. Delaitre, P.; Lavandier, C.; Dedieu, R.; Gey, N. Meaning of quiet areas in urban context through people viewpoints. In Proceedings of the Acoustics 2012 Nantes Conference, Nantes, France, 23-27 April 2012.

16. Lavandier, C.; Delaitre, P. Individual and shared representations on "zones calmes" ("quiet areas") among the French population in urban context. Appl. Acoust. 2015, 99, 135-144.

17. Botteldooren, D.; Andringa, T.; Aspuru, I.; Brown, A.L.; Dubois, D.; Guastavino, C.; Kang, J.; Lavandier, C.; Nilsson, M.; Preis, A. From Sonic Environment to Soundscape. In Soundscape and the Built Environment; Kang, J., Schulte-Fortkamp, B., Eds.; CRC Press: Boca Raton, FL, USA, 2015; pp. 17-43.

18. Summerfield, C.; Egner, T. Expectation (and attention) in visual cognition. Trends Cogn. Sci. 2009, 13, 403-409.

19. Gunnarsson, B.; Knez, I.; Hedblom, M.; Sang, Å.O. Effects of biodiversity and environment-related attitude on perception of urban green space. Urban Ecosyst. 2016, pp. 1-13.

20. Gygi, B.; Shafiro, V. The incongruency advantage for environmental sounds presented in natural auditory scenes. J. Exp. Psychol. Hum. Percept. Perform. 2011, 37, 551-565.

21. Pezdek, K.; Whetstone, T.; Reynolds, K.; Askari, N.; Dougherty, T. Memory for real-world scenes: The role of consistency with schema expectation. J. Exp. Psychol. Learn. Mem. Cogn. 1989, 15, 587-595.

22. Huron, D.B. Sweet Anticipation: Music and the Psychology of Expectation; MIT Press: Cambridge, MA, USA, 2006.

23. Botteldooren, D.; Filipan, K.; Boes, M.; De Coensel, B. How the meaning a person gives to tranquility could affect the appraisal of the urban park soundscape. In Proceedings of the 43rd International Congress on Noise Control Engineering (InterNoise), Melbourne, Australia, 16-19 November 2014. 
24. Delaitre, P.; Lavandier, C.; Cance, C.; Pruvost, J. What is the definition for the French word calme in the European Directive related to "Quiet Areas"? A lexicographic study from the 16th century until today. Acta Acust. United Acust. 2012, 98, 734-740.

25. Jolliffe, I.T. Principal Component Analysis, 2nd ed.; Springer Series in Statistics; Springer: New York, NY, USA, 2002.

26. Abdi, H. Factor rotations in factor analyses. In The SAGE Encyclopedia of Social Science Research Methods; Lewis-Beck, M.S., Bryman, A., Futing Liao, T., Eds.; SAGE Publications: Thousand Oaks, CA, USA, 2003.

27. Brown, S.R. A primer on Q methodology. Operant Subj. 1993, 16, 91-138.

28. De Coensel, B.; Sun, K.; Wei, W.; Van Renterghem, T.; Sineau, M.; Ribeiro, C.; Can, A.; Aumond, P.; Lavandier, C.; Botteldooren, D. Dynamic noise mapping based on fixed and mobile sound measurements. In Proceedings of the 10th European Congress and Exposition on Noise Control Engineering (Euronoise), Maastricht, The Netherlands, 31 May-3 June 2015; pp. 2339-2344.

29. Yu, L.; Kang, J. Factors influencing the sound preference in urban open spaces. Appl. Acoust. 2010, 71, 622-633.

30. Axelsson, Ö.; Nilsson, M.E.; Hellström, B.; Lundén, P. A field experiment on the impact of sounds from a jet-and-basin fountain on soundscape quality in an urban park. Landsc. Urban Plan. 2014, 123, 49-60.

31. Davies, W.J.; Adams, M.D.; Bruce, N.S.; Cain, R.; Carlyle, A.; Cusack, P.; Hall, D.A.; Hume, K.I.; Irwin, A.; Jennings, P.; et al. Perception of soundscapes: An interdisciplinary approach. Appl. Acoust. 2013, 74, $224-231$.

32. Hall, D.A.; Irwin, A.; Edmondson-Jones, M.; Phillips, S.; Poxon, J.E. An exploratory evaluation of perceptual, psychoacoustic and acoustical properties of urban soundscapes. Appl. Acoust. 2013, 74, 248-254.

33. Jones, E.; Oliphant, T.; Peterson, P. SciPy: Open source scientific tools for Python. Available online: http://www.scipy.org/ (accessed on 11 November 2016).

34. Seabold, S.; Perktold, J. Statsmodels: Econometric and Statistical Modeling with Python. In Proceedings of the 9th Python in Science Conference, Austin, TX, USA, 28-30 June 2010.

35. De Coensel, B.; Botteldooren, D. The quiet rural soundscape and how to characterize it. Acta Acust. United Acust. 2006, 92, 887-897.

(C) 2017 by the authors; licensee MDPI, Basel, Switzerland. This article is an open access article distributed under the terms and conditions of the Creative Commons Attribution (CC-BY) license (http:/ / creativecommons.org/licenses/by/4.0/). 